\title{
Toward a "constitution" for behavioral policy-making
}

\author{
Marco Fabbri $^{1}$ (D) Michael Faure Ma $^{2,3}$
}

Received: 14 October 2017 / Accepted: 27 April 2018 / Published online: 4 May 2018 (C) The Author(s) 2018

\begin{abstract}
Behavioral policy interventions aimed at redirecting individuals' behavior toward optimal choices are characterized by an important issue which is often overlooked: the lack of an instrument to define what "optimal" means. If agents are subject to behavioral biases leading them to make "wrong" choices, the policymaker can no longer rely on the revealed preferences approach (e.g., what people choose is what people prefer) for defining a welfare criterion. In this article, we reiterate the argument put forward by some scholars that choosing a suitable welfare criterion once the link between observed choices and individuals' preferences is broken becomes a problematic task. We review the state of the art in the literature and the possible approaches proposed to overcome the problem, concluding that a solution has not yet been reached. Moreover, we argue that the lack of an established welfare criterion characterizing behavioral policy-making could pave the way to government wanting to restrict individual freedom. In the absence of any legislative constraint for the executive, stating that what individuals choose is not what they prefer in principle justifies any freedom-reducing government intervention, since choices can be arbitrarily labeled "sub-optimal" or "welfare-reducing." To avoid this risk without turning down the potential of behavioral policy-making, we propose that an independent committee establishes ex ante procedural rules and domains where behavioral policy-making can be implemented. The article suggests some possible examples of normative provisions characterizing this constitution-type document, such as the selective identification of the only sectors where behavioral policies could be
\end{abstract}

Marco Fabbri

m.fabbri@uva.nl

1 University of Amsterdam, Nieuwe Achtergracht 166, Room A.5-16, 1018 WV Amsterdam, The Netherlands

2 Faculty of Law, METRO, University of Maastricht, Maastricht, The Netherlands

3 Erasmus School of Law, Erasmus University Rotterdam, Rotterdam, The Netherlands 
effectively applied, the periodic evaluation of policy effects, and the use of sunset clauses.

Keywords Law and economics $\cdot$ Nudging $\cdot$ Public policy $\cdot$ Revealed preferences

JEL Classification $\mathrm{K} 30 \cdot \mathrm{K} 40$

\section{Introduction: the behavioral revolution and its unsolved issues}

Whereas the economic approach to law has probably been the most powerful intellectual movement affecting law and policy-making in the twentieth century, the beginning of the twenty-first century seems to be marked by cognitive and social psychology. Researchers such as Tversky and Kahneman showed that many individuals are subject to a variety of cognitive heuristics and biases as a result of which they may not always maximize their expected utility. ${ }^{1}$ Given that the direction of the aforementioned deviations from the rational (in an economic sense) behavior is often predictable, scholars have been able to produce models of decision making that include these behavioral anomalies. ${ }^{2}$

These insights from cognitive psychology have to a large extent been incorporated into the traditional economic analysis of law through the seminal work of Sunstein and Jolls, ${ }^{3}$ leading to a new domain referred to as "behavioral law and economics." The goal of behavioral law and economics "is to offer better predictions and prescriptions about law based on improved accounts of how people actually behave."4 Although there was originally some opposition to this behavioral approach, ${ }^{5}$ leading law and economics scholars now largely recognize the importance of cognitive psychology also for the domain of law and economics. ${ }^{6}$ More recently, governments and policy-makers have become interested in the implementation of the insights coming from behavioral sciences into the rule-making process. Indeed, the recently established area of behavioral policy-making ${ }^{7}$ aims to enhance policies that counteract

\footnotetext{
1 See Tversky and Kahneman (1974) and Kahneman et al. (1982).

2 Ariely and Jones (2008) and Camerer and Loewenstein (2004).

3 See inter alia Jolls (1998), Jolls et al. (1998), Sunstein (1997, 1999, 2000).

4 Jolls $(1998,1654)$.

5 See more particularly Posner (1998).

${ }^{6}$ Richard Epstein, for example, held: "There is little doubt that the major new theoretical approach to law and economics in the past two decades does not come from either field, but from the adjacent discipline of cognitive psychology, which has now moved into behavioral economics" (Epstein 2008).

7 From the outset, we should formulate one warning as far as the terminology is concerned. There is, on the one hand, a broad discussion on using insights of behavioral economics at the policy level. This is generally referred to as "behavioral policy-making." However, after the publication in 2008 of Thaler and Sunstein's famous book Nudge: Improving Decisions About Health, Wealth and Happiness, the term "Nudging" had gained increasing popularity. Nudging interventions act by modifying aspects of a choice architecture that alters people's behavior in a predictable way, with the key characteristic that nudges do not forbid any options or significantly change agents' economic incentives. While nudging and behavioral policy-making are sometimes used as synonymous in the literature, nevertheless we want to emphasize that nudging interventions are only one specific type of the several behavioral policies which
} 
biases and redirect patterns of behavior that are supposed to hurt people. ${ }^{8}$ Therefore, the goal of behavioral policy-making is to correct decisions that produce "sub-optimal" outputs and to redirect them toward alternatives that make people "better off." However, what does "optimal" mean in the context of behavioral policy-making?

This article focuses on the important methodological problem of identifying a suitable welfare criterion for behavioral policy-making. We will argue that, despite the fact that behavioral interventions are implemented at increasing rate, no convincing theory has been advanced yet regarding how to identify the "optimal" choice and what it means to make individuals "better off." "Traditional economic analysis relies on Samuelson's theory of revealed preferences to determine its welfare criterion. ${ }^{10}$ According to this theory, by observing the choices of individuals it is possible to discover their true underlying preferences. However, behavioral policies cannot rely on this preference-based criterion for optimality. ${ }^{11}$ In fact, neoclassical utility maximization theory is based on the assumption that whatever action an individual voluntarily chooses must be welfare enhancing. Thus, it does not make sense to evaluate whether an agent is making a sub-optimal decision using a benchmark measure built on the premise that people always make optimal choices. Hence, the behavioral revolution left open a key normative question: which welfare criterion should be adopted for behavioral policy-making?

It is important to emphasize that the problem of finding a suitable welfare criterion is a distinctive feature of behavioral policy-making. This problem is qualitatively different from issues faced by a policy-maker who assumes rational agents, such as the difficulty in choosing "optimal" levels of taxes or incentives. In fact, it is well known that fully rational (in economic sense) agents can still achieve a sub-optimal social outcome in cases where externalities or public goods are present. Policy-makers called to correct these market failures might face severe practical problems. For instance, imagine that a policy-maker wants to achieve an "optimal" level of pollution by imposing an environmental tax on a firm that engages in a polluting activity. To achieve optimality, the tax has to be set in such a way that the firm is fully internalizing the benefits and the costs of its activity. Setting the right tax might be complicated in practice, since the policy-maker has no direct access to information regarding the costs of pollution and the benefit of environmental protection. Therefore, the lack of a price for certain

\footnotetext{
Footnote 7 (continued)

policy-makers could use to direct people toward better choices. Indeed, behavioral policy-making goes well beyond nudges. In particular, behavioral policy-making, besides using freedom preserving and usually low-cost interventions that modify the choice architectures characteristic of nudges, also supports a broader range of policy instruments that include traditional forms of intervention (e.g., regulations and incentives). In Sect. 2, we provide a deeper review of the characteristics of nudging as a special subset of behavioral policy. Please notice that the critical reflections which can be found in the literature, and that we summarize in the following sections, refer both to behavioral policy-making in general and to nudging. See further on the definition of nudging also Hansen (2016).

8 Loewenstein and Haisley (2008).

9 See, for instance, Nussbaum (1997).

10 Samuelson (1938).

11 This point is made clear by Mullane and Sheffrin $(2012,10)$.
} 
commodities that unambiguously reveals its market value imposes to the policymaker the need to engage in some estimation procedures to indirectly retrieve this information. For instance, the market value of clean air can be estimated by identifying a set of residential houses sharing identical characteristics and comparing market prices of those located in proximity of a landfill with those far away from it. The problem of achieving optimal pollution levels is an information problem: as long as through some clever procedure the policy-maker acquires the market evaluation of a certain good as revealed by consumers' choices, she can identify what the optimal level of pollution is (and so, how the environmental tax should be set). Conversely, this is not the case in the context of behavioral policymaking. Indeed, as we explain in detail in the next sections, the pillar of behavioral policy-making is that observed choices do not necessarily reflect consumers' underlying preferences. Therefore, even if scholars would agree on a procedure to estimate the market values of a good as revealed by consumers' choices, the problem of defining what "optimal" means would not be solved. So far few theories have been proposed, but no consensus has been reached, regarding how to identify these preferences.

We contribute to the debate on the methodological problems of behavioral policymaking by taking a law and economics approach. Our contribution is twofold. First, we raise awareness against an important issue in behavioral policy-making that is at times overlooked by scholars and practitioners. Some recent contributions (reviewed in the next section) emphasize the problem of identifying individuals' preferences faced by behavioral policy-making. We focus on the link between abandoning revealed preferences and the possibility for governments to make use of behavioral interventions to restrict citizens' freedom. The revealed preferences approach, despite its aforementioned limitations set out by cognitive psychology, guarantees the respect of individuals' freedom of choices. Conversely, rejecting the idea that people choose what they prefer without providing a solid alternative theoretical framework in principle countenance any freedom-reducing intervention, on the basis that individuals' choices are "mistakes" or "products of biases." In this article, we stress that abandoning revealed preferences does not simply create a methodological problem of preferences identification. Instead, in the absence of clear rules regulating the use of behavioral policies, it might also affect liberty and individual freedom.

In the second part of the article, we propose a solution to the problems caused by the lack of a suitable welfare criterion. On the one hand, we aim at leaving open for policy-makers the opportunity to make use of the potential of behavioral policymaking and, on the other hand, we want to limit the possibility for the executive to justify freedom-reducing interventions. We argue that, for implementing behavioral policies in a safe way, the boundaries and domains of application of behavioral policy-making should be clearly defined ex ante, and we emphasize that it is necessary to agree upon precise procedural requirements. We therefore propose that behavioral interventions must adhere to guiding principles of the highest order, such as imposing special procedural requirements and including mandatory public participation to implement changes. By defining the rules of the game, the scopes and the limits of 
application, these "constitutional-type" guiding principles should regulate behavioral policy-making. ${ }^{12}$

We will proceed as follows. In the next section, we sketch the rise of the behavioral approach into policy-making. In the same section, we also summarize the criticisms that have been formulated by the scientific community on the use of behavioral interventions. Next, we focus on the methodological problem of behavioral policy-making and the many unresolved issues (3). We therefore propose a solution which focuses on procedures and rules (hence a "constitution") that limit the possibility for the government to abuse its position (4). The conclusion summarizes the content of our proposal (5).

\section{Behavioral policy-making}

\subsection{A movement on the rise}

There is an increasing popularity of using behavioral policy-making tools among policy-makers. Behavioral insight teams are at work inter alia in the USA, the UK and a few other countries are equally opening branches for applied behavioral policy-making, including the EU Commission. ${ }^{13}$

The US government recently began a process for institutionalizing the implementation of behavioral insights into policy-making. In September 2009, Chicago Professor Cass Sunstein - the author of various influential articles on behavioral policy-making and co-author of the best seller Nudge - was appointed Director of the White House Office of Information and Regulatory Affairs (OIRA). The objective was to make the US regulatory system as sensible and user-oriented as possible. Under Sunstein's mandate, terminated in 2012, OIRA promoted the use of disclosure and implemented important simplifications in the regulatory process. In an attempt to push further the implementation of behavioral policy-making, in September 2015 President Obama issued the Executive Order "Using Behavioral Science Insights to Better Serve the American People" that requires US Federal Agencies to implement behavioral insights when designing government policies. ${ }^{14}$

\footnotetext{
12 As it will become clear in the remainder of the article, we obviously refer to a "constitution" in the material sense, being a document that provides precise and strict guiding principles and procedures. However, it should be emphasized that we are not pleading for including behavioral policy-making guiding principles in existing constitutions or changing/amending those constitutions. Instead, we refer to a "constitution for behavioral policy-making" to stress that these principles should not merely be guidelines in the way they already exist, for example, by the UK Office of Fair Trading, but that they should be of a much higher order.

13 In this section, we focus on behavioral policies either that are explicitly designed on the basis of previous behavioral evidence or that are implemented after a randomized control-trial testing procedure. However, as noted by Lourenço et al. in the Behavioural Insights Applied to Policy EU Report 2016, there are also a large number of behavioral policy initiatives whose design implicitly incorporates behavioral insights without, however, referring to behavioral theories or being subject to ad hoc testing.

14 White House Executive Order, available at https://www.whitehouse.gov/the-press-office/2015/09/15/ executive-order-using-behavioral-science-insights-better-serve-american (accessed 5-3-2016).
} 
Even before this, the US government had implemented several federal regulations that incorporate behavioral insights. One of the fields targeted by important behavioral interventions concerns pension policy. The US Pension Protection Act (PPA) of 2006 makes use of defaults in order to increase the rate of savings among workers. ${ }^{15}$ Moreover, the PPA has also a default of "contribution escalators," hence encouraging participants to slightly increase over time their contribution to the pension fund. The mechanism was implemented after an assessment of the Save More Tomorrow (SMT) plan, whereby savings decisions resulting from voluntary participation in a 401(k) plan with yearly escalations in contribution rates were significantly increasing. ${ }^{16} \mathrm{~A}$ widespread use of behavioral policy interventions can be found in the Patient Protection and Affordable Care Act (PPACA) 2010. For instance, PPACA regulation requires menu-labeling to disclose nutrient information. Similarly, the institution of the White House Task Force on Childhood Obesity (WHTFCO). WHTFCO's objective is to reduce tweens' health problems associated with an unhealthy lifestyle by changing social norms through the manipulation of saliency. The "Spot the Block" campaign, where young people are motivated to use the nutrition facts label ("the block") when comparing foods and the mandate for middle schools to increase options for healthful eating are other examples of behavioral interventions. At the state level, an increasing number of campaigns leverage social influence and social norms effects to achieve the regulator's objective. A highly cited example is the "Don't Mess with Texas" campaign against littering, that is generally considered very successful. ${ }^{17}$ A second famous example is the OPOWER project, where letters that convey social norms messages raise awareness in households of the need to decrease energy consumption. ${ }^{18}$

Also, European Member State governments and the European Commission are increasingly active in bringing behavioral insights into legislation and regulatory interventions, as well as in establishing and developing organizations that institutionalize this implementation. The Directive 2011/83 on consumer rights ${ }^{19}$ constitutes the first attempt, followed by many other interventions in subsequent years, to explicitly implement findings of behavioral sciences into policy-making. In 2014, a Foresight and Behavioral Insight Unit at the Joint Research Centre of the European Commission was created. At a national level, in 2010 the UK established the Behavioural Insight Team (BIT), which as of today has performed more than 150 randomized control-trial evaluations of behavioral policy interventions. Following UK examples, also Netherlands, Germany, France and Denmark established national organizations with the task to incorporate behavioral insights into policy-making and in other European countries, like Austria and Finland, the possibility of establishing similar institutions is currently under discussion. The European Commission Report "Behavioural Insights Applied to Policy" published in 2016 identifies

\footnotetext{
15 Beshears et al. (2010).

16 Thaler and Benartzi (2004).

17 Thaler and Sunstein (2008, 60-61).

18 Congdon et al. (2011).

19 Directive 2011/83 of 25 October 2011 on consumer rights, OJ L 304/64 of 21 November 2011.
} 
more than 200 examples of behavioral policy initiatives in EU member states in fields such as competition, consumer protection, employment, energy, environment, health, finance, taxation, transport. ${ }^{20}$ The report highlights that the number of behavioral interventions is rapidly growing.

International organizations are also increasingly encouraging the application of behavioral sciences principles to policy-making. In 2014, the OECD published a report engaging in a systematic review of behavioral policy applications across the world. ${ }^{21}$ The 2015 World Development Report of the World Bank highlights the need to advise development policies with findings from behavioral sciences in order to increase the effectiveness of development aids. ${ }^{22}$

\subsection{The big push to behavioral policy-making: nudging}

One way of proceeding that has become very popular for implementing behavioral policies, bypassing at the same time the potential disadvantages of direct regulatory intervention, has been the introduction of so-called libertarian paternalism, nudging $^{23}$ or asymmetric paternalism. ${ }^{24}$ A nudge is a specific type of behavioral policy intervention that alters people's behavior in a predictable way but, in contrast to other behavioral policy-making approaches, it operates by modifying the "choice architecture" of a decision situation, while preserving the same set of decision options and keeping unchanged the costs associated with a decision. ${ }^{25}$

The difference between nudging and the broader set of behavioral policy-making tools can be illustrated with an example. Installing a device in a car that does not allow it to start if the driver is positive to an alcohol test is not a nudge, even if the installation is imposed by a central authority, or if it is voluntarily implemented by the driver. Indeed, such a device actually changes the choice set of the agents. (The drunk person who would "rationally" prefer to drive can no longer do so.) This is a traditional behavioral intervention, but not of the nudging type. It is rather an intervention within the framework of "mindless economics" 26 where a sophisticated agent uses a commitment device that restricts his choice set because he anticipates that, once in an altered state of mind, he would just start the car. Conversely, an example of nudging is placing at the entrance of a cafeteria salads and fruits before less healthy foods. Since the layout of food influences people's choice of consumption, placing low-fat food first promotes healthy outcomes (inattentive or uninterested people consume more salads and fruits) without restricting the freedom of choice of the others. (Individuals preferring less healthy food do not have to make extra effort or pay higher prices to consume it.)

The charm of the libertarian paternalistic approach is that it seems to be less intrusive than direct government regulation and that it would merely nudge individuals

\footnotetext{
${ }^{20}$ Lourenço et al. (2016).

21 Lunn (2014).

22 The World Bank (2015).

23 Thaler and Sunstein $(2008,72)$.

24 Camerer et al. (2003).

25 Thaler and Sunstein (2003).

26 See Gul and Pesendorfer (2005).
} 
into better decisions without directly forcing or imposing additional costs on them. ${ }^{27}$ Libertarian paternalism would softly nudge individuals toward the "right" decision, for example by sending to households letters that convey social norms messages aimed at reducing energy consumptions ${ }^{28}$ or by increasing savings for retirement exploiting the "sticky" character of the savings retirement plan for employees that is offered as a default. ${ }^{29}$

\subsection{Critiques to behavioral policy-making}

Behavioral policy-making, including nudging, attracts widespread criticism, and some scholars are reluctant to support the use of the behavioral approach to formulate policy recommendations. ${ }^{30}$ Lawyers have argued that behavioral interventions may be undemocratic (as they are usually a tool for the executive) ${ }^{31}$ and that formal legal review of measures based on behavioral policy-making may be lacking. ${ }^{32}$ Some disapprovals relate to the fact that it would violate the autonomy of choice of individuals, harming their liberty, ${ }^{33}$ hence potentially even violating human rights. ${ }^{34}$ Others hold that behavioral policies, especially when camouflaged as seemingly innocent nudges, are manipulative ${ }^{35}$ and violating human dignity. ${ }^{36}$

It has also been argued that behavioral economics may point at a variety of human errors, but that these do not necessarily imply regulatory interventions. According to this position, before engaging in behavioral interventions it should first be examined how individuals are themselves capable of (partially) remedying errors by learning in order to improve their situation. ${ }^{37}$ John List, for instance, showed in various experiments that, as participants gain experience in market transactions, some of the cognitive biases disappear. ${ }^{38}$ Also Korobkin and Ulen held that the legal implications of particular behavioral phenomena are not clear cut at all. ${ }^{39}$

\footnotetext{
27 In the words of Thaler and Sunstein: "Libertarian paternalism is a relatively weak, soft, and non-intrusive type of paternalism because choices are not blocked, fenced off, or significantly burdened. If people want to smoke cigarettes, to eat a lot of candy, to choose an unsuitable healthcare plan, or to fail to save for retirement, libertarian paternalists will not force them to do otherwise-or even make things hard for them. Still, the approach we recommend does count as paternalistic, because private and public choice architects are [...] self-consciously attempting to move people in directions that will make their lives better. They nudge." (Thaler and Sunstein 2008, 5-6).

28 Congdon et al. (2011).

29 Choi et al. (2003) and Carroll et al. (2009).

${ }^{30}$ For a summary of the critics in this respect, see inter alia Hansen and Jespersen (2013) and Tor (2008, 318-325).

31 McCrudden and King $(2015,123)$ and Hansen and Jespersen $(2013,5)$.

32 Van Aaken (2015a).

33 Rebonato (2012).

34 Alemanno and Spina $(2014,446)$.

35 Young (2012).

36 McCrudden and King (2015, 100-104).

37 Epstein $(2006,130)$.

38 List (2003, 2006).

39 Korobkin and Ulen (2000, 1097).
} 
Behavioral policy-making is also criticized from the perspective of social welfare. Ogus held that there could still be welfare maximization notwithstanding the biases and hence no need for regulatory intervention. ${ }^{40}$ Moreover, he equally held that, if such an intervention took place, the question still arises whether the benefits outweigh the costs. Another criticism relates to the central point in our argument, being that it is not clear why the regulator or the "choice architect" would know better than individuals what is good for them. In the words of Glaser, "Public errors are as realistic a problem as private errors." ${ }^{41}$ For instance, a report of the Science and Technology Select Committee of the Upper house of the United Kingdom Parliament in 2010 and 2011 makes clear that behavioral policy-making diverts governments from its responsibility to use other, more effective instruments and that it reduces opportunities for public deliberation and democratic discourse in favor of non-transparent, technocratic manipulation. ${ }^{42}$

We mentioned above the criticism that an integrated theory replacing the neoclassical welfare economics framework is not provided by the behavioral approach. ${ }^{43}$ Using similar arguments, Gigerenzer pointed at the fact that behavioral (law and) economics was questioned "for merely listing anomalies without providing a theory." 44 In the next section, we discuss in detail the problem caused by the lack of a robust theoretical framework for behavioral policy-making.

\section{The problem of setting the welfare criterion}

A fundamental step in the economic analysis of social policy is concerned with evaluating the desirability of policy effects, that is, to produce normative statements. This normative analysis is the core of welfare economics, the branch of economic science evaluating well-being from the allocation of productive factors in terms of economic efficiency and desirability or resources allocation. According to social welfare philosophy (or utilitarian philosophy), it is necessary to evaluate different states of the world in terms of their end-state distributional results. In fact, the purpose of welfare economics is to obtain a social ordering over alternative possible states of the world, thus promoting, when possible, normative principles.

The traditional economic approach relies on a welfare criterion based on the theory of revealed preferences. ${ }^{45}$ According to this theory, the preferences of individuals can be deducted from their observed behavior. Hence, standard consumer theory allows extrapolating public policy outcomes from the observation of private choices. A common way of interpreting the neoclassical approach is that people

\footnotetext{
40 Ogus (2006, 250-252).

41 Glaser $(2006,134)$.

42 House of Lords, Science and Technology Select Committee Behaviour Change, Report (2011), HLpaper 179, cited by McCrudden and King $(2015,84)$.

43 See also Tor $(2008,291)$.

44 Gigerenzer $(2005,61)$.

45 Samuelson (1938).
} 
have well-defined preference rankings and these rankings form the basis for welfare analysis. A rational agent makes decisions as if he was able to consider and process all the available information, to engage in cost-benefit evaluations and to regulate present and future consumption according to his expectations. By relying on the revealed preferences approach, neoclassical welfare economic analysis does not distinguish between individuals' choices and well-being. As a consequence, given his preferences, constraints and available information, the agent would end up making the choice that guarantees him the maximum (expected, if we talk about future outcomes) well-being. Hence, the neoclassical policy analyst derives which policy choice to make from the observation of private consumption choices made by individuals.

As we previously indicated, one result of the behavioral approach is that the assumption that we can deduct what is best for individuals from their actual behavior (revealed preferences) does not hold any longer, since the behavioral studies show precisely that individuals do not always make optimal choices. Experimental psychologists and behavioral economists documented that in some situations of great economic relevance, individuals systematically depart from economists' neoclassical assumption of rationality. ${ }^{46}$ Researchers found that decision-making processes are the result of two coexisting and interacting mental systems: an impulsive, shortterm focused one ("System 1") and a reflexive, long-term oriented one ("System 2"). ${ }^{47}$ While decisions made by System 2 would be fairly consistent with neoclassical economic predictions, nevertheless the influence of System 1 is responsible for the aforementioned biases. ${ }^{48}$ The problem with System 1 is that, when people make decisions on the basis of emotions, neglecting information or attaching exaggerated weight to the present, they might end up making choices contrary to their own self-interest. For example, they could take excessive risks, make decisions that they will later regret or forego possibilities of high future gains in order to avoid small immediate costs. ${ }^{49}$ The basic problem of those heuristics and biases is that individuals apparently often make decisions that seem sub-optimal from the perspective of maximization of expected utility. In some cases, they behave differently than what their preferences would lead us to expect.

However, recognizing that individuals might not choose what they want creates problems with respect to the identification of a suitable welfare criterion that the policy-maker uses to maximize social welfare. So far, among behavioral economists no consensus regarding the standards and criteria to adopt has been emerged. Broadly speaking, it is possible to identify two schools of thought. On the one hand, in the opinion of some scholars policy evaluations must maintain a strict adherence to the doctrine of revealed preferences. According to this view, observed "anomalies" in

\footnotetext{
${ }^{46}$ For an overview, see, for example, Beshears et al. (2008), Della Vigna (2009), Kahneman (2003) and Akerlof and Shiller (2010).

47 See Kahneman (2011) for a discussion of this point; see Hsu et al. (2005) for a contribution that identifies the neural correlates responsible for the activation of different areas of the brain connected with the two systems.

48 Loewenstein and Haisley (2008).

49 Camerer et al. (2004).
} 
individuals' decision making should be explained by an extension of the preferences domain, as, for example, in Gul and Pesendorfer. ${ }^{50}$ On the other hand, other researchers investigated the possibility to relax, modify, or depart from the principle of revealed preferences in conducing welfare analysis. In Sect. 3.1, we review the attempts to relax the assumptions of neoclassical economic theory and the proposed solutions, highlighting problematic issues as well as open questions in Sect. 3.2.

\subsection{Relaxing the assumptions at the basis of welfare economics analysis}

Following Bernheim and Rangel, ${ }^{51}$ we can say that neoclassical welfare economics analysis is based on four key assumptions:

1. Coherent preferences: each individual has coherent and well-organized preferences.

2. Preference domain: the set of state-contingent consumption paths that an individual exhibits during his life constitutes his preferences domain.

3. Fixed lifetime preferences: individuals do not change over time, or across states of the world, the rank order of lifetime state-contingent consumption paths.

4. No mistakes: Each individual always choose the preferred option among the feasible ones given his choice set.

In the remainder of this section, we review how scholars identified behavioral anomalies that violate these four assumptions and the attempts to produce theories that relax each of them.

\subsubsection{Relaxing coherent preferences}

The assumption of coherent preferences implies that people's decisions are well defined and that they are not influenced by irrelevant details or by the context in which they are taken. However, starting with the pioneering work of Tversky and Kahneman, ${ }^{52}$ behavioral scientists show that observed choices are highly contextdependent and that framing greatly influences individuals' decision. Given these observations, some scholars proposed welfare criteria that are no longer based on the notion of allocation of resources. These contributions introduce a separation between positive models describing choices and normative models describing welfare. $^{53}$

Along this line the capabilities approach was developed, first advocated by $\mathrm{Sen}^{54}$ and later by Nussbaum. ${ }^{55}$ This approach rejects the standard preference-based

$50 \mathrm{Gul}$ and Pesendorfer (2001, 2004).

51 Bernheim and Rangel (2012).

52 Tvesky and Kahneman $(1981,1986)$.

53 See Kahneman (2011, 269-374).

54 Sen $(1985,1999)$.

55 Nussbaum (2001). 
measurement of welfare on the basis of the concept of hedonic adaptation: People adjust individual preferences and expectations to social conditions and to the surrounding environment. Therefore, choices made by agents in a specific situation might not just reveal individual preferences but instead could show that people adapted their preferences to the specific circumstances in an attempt to achieve feasible goals. Sen and Nussbaum argue in favor of a normative theory of welfare that is based on what people are capable of achieving, given surrounding social conditions and the opportunity offered to them. Nussbaum goes further proposing a set of fundamental human capabilities on which this theory should be based.

A notion of welfare based on opportunities that share some common points with the capabilities approach is the one advocated by Sugden. ${ }^{56}$ In his contribution, Sugden formulates a rigorous welfare criterion that justifies the use of opportunities as welfare standard. Both the capabilities approach and the opportunity criterion solve the problem of hedonic adaptation and overcome the revealed preference theory assumption that choices are always welfare enhancing. Nonetheless, these criteria create for the policy-maker the problem of determining which capabilities or opportunities must be valued.

Adler (2012) argues in favor of the concept of "extended preferences" as the criterion for behavioral policy-making. According to the author, the evaluations of the policy-maker should consider as a foundational criterion agents' "fully informed, fully rational extended preferences regarding life-histories, life history lotteries, and comparisons to non-existence" (p. 261).

Finally, Beshears et al. (2008) propose a distinction between revealed and "normative" preferences, also arguing that the concepts do not necessarily coincide. The authors specify a set of situations and factors that make more likely to register this separation: passive choice, complexity, limited personal experience, third-party marketing, and intertemporal choice. The article then discusses frameworks that could contribute to estimate normative preferences when they do not coincide with revealed preferences, such as structural estimation, active decisions, and the use of reported preferences.

\subsubsection{Relaxing preference domain}

It is possible to identify two classes of behavioral anomalies that are inexplicable through the neoclassical approach but that allow for a welfare analysis if one extends the preference domain. The first anomaly involves temptation and self-control, the second is constituted of social preferences.

Empirical evidence suggests that in a variety of situations individuals engage in time-inconsistent choices and that they rely on various forms of pre-commitment. ${ }^{57}$ The solution proposed by Gul and Pesendorfer ${ }^{58}$ consists of defining the preference domain over both allocations and choice sets. If individuals are sophisticated and

\footnotetext{
56 Sugden (2004).

57 Ameriks et al. (2007).

58 Gul and Pesendorfer (2001).
} 
can correctly forecast the effect of future temptations, they could prefer to constrain future alternatives even when constraints should not have any impact on actual choices. For instance, a sophisticated individual wanting to save for the Christmas period could correctly forecast his inability to avoid shopping during the summer sale season. Therefore, he could prefer a commitment device that limits her future choice set. For example, she could opt for a special savings account that, holding constant the benefits offered, additionally imposes the payment of a penalty for money withdrawn before the month of December. ${ }^{59}$ It is important to notice that the Gul-Pesendorfer framework, however, does not imply a departure from the revealed preference approach. Indeed, individuals maintain, as in the neoclassical framework, the same lifetime preferences ranking at every moment in time (e.g., without the penalty for withdrawal, the individual would recognize as welfare-maximizing the decision to shop during the summer sales, and she explicitly imposes a constraint because she understands the value of temptation). Therefore, welfare evaluation could be performed by discovering the revealed preferences, assuming that the policy analyst imposes a suitable structure on the choice data.

Behavioral anomalies within the class of social preferences include sharing allocations even without reputation or reciprocity, ${ }^{60}$ the equality concerns ${ }^{61}$ and the effects of conformity and social influence. ${ }^{62}$ Behavioral economists proposed models where individuals' preferences are defined both over their own and other individuals' consumption bundles. Again, this procedure does not imply abandoning the revealed preferences approach: once a suitable structure is imposed on consumption data, the policy analyst can infer individuals' preferences by observing their consumption choices.

\subsubsection{Relaxing fixed lifetime preferences}

The aforementioned evidence of time-inconsistent behavior and various forms of pre-commitment motivate also the relaxation of this assumption. Broadly speaking, scholars have adopted two modeling strategies. One possible strategy consists of endowing individuals with well-behaved lifetime preferences that vary at different points in time. ${ }^{63}$ Alternatively, one can allow lifetime preferences to be different across states of nature. ${ }^{64}$ Once these preferences have been measured, then in order to conduct welfare analysis the policy analyst has to aggregate them. Aggregating these preferences within a single individual requires a procedure similar to the aggregation of preferences in a multi-agent situation. (Indeed, here the modeling strategy implies that we aggregate over "multiple selves.") A branch of the literature

\footnotetext{
59 Ayres (2010).

60 See Engel (2011) for a meta-analysis of the Dictator game.

61 For example, Fehr and Schmidt (1999).

62 For literature reviews, see Cialdini and Trost (1998) and Fabbri and Carbonara (2017).

63 Laibson (1997) and O'Donoghue and Rabin (2001).

64 Loewenstein (1996) and Loewenstein and O'Donoghue (2004).
} 
exploits this analogy. ${ }^{65}$ Another branch of the literature instead proposes to base welfare analysis on the selection of reasonably stable components of preferences. ${ }^{66}$ Bernheim and Rangel ${ }^{67}$ provide a formal justification for the use of this criterion.

\subsubsection{Relaxing no mistakes}

Evidence that preferences and choices diverge motivates a relaxation of the fourth assumption. First of all, there are cases where almost everyone agrees that individuals do not necessarily make choices following their own self-interest, as in the cases of children or agents who are affected by serious mental disorder. More generally, any of the behavioral anomalies we mention as a motivation for the relaxation of the first three assumptions could justify the relaxation of the fourth.

\subsection{What welfare criterion for behavioral policy-making? Solution proposed and problems}

Neoclassical welfare economics restricts the source of utility to individual's judgments and to goods and services that he himself consumes. Therefore, the policy analyst operating in the framework of welfare economics has to discard any other aspect not affecting individuals' utility. Hence, what is good or bad for society reflects what is good or bad for the individuals belonging to the society. The analyst is supposed to "suspend his individual value judgment and act as each individual's proxy." 68

Conversely, a common distinctive tract of all the attempts to relax neoclassical economic assumptions mentioned above is the division between a positive analysis of policy effects and a normative evaluation of well-being. This division allows behavioral policy analysts to engage in issues of great social importance. They can, for example, meaningfully address the questions raised by self-destructive behaviors or make a sense of the claim that the average household saves "too little" for retirement.

However, departing from the revealed preference approach and assuming that people do not choose what they prefer raises problematic issues. The revealed preferences approach guarantees individuals' freedom of choice, and it protects individuals' choices against a priori condemnations. Once this approach is abandoned, in principle governments become entitled to the possibility to condemn individuals' choices and to set "beneficial" restrictions of personal freedom. Therefore, given this possibility, the determination of precise standards of evidence and procedures for departing from the principle of revealed preferences and the determination of an alternative welfare criterion acquires special importance in behavioral policy-making.

\footnotetext{
65 E.g. Laibson (1997).

66 O’Donoghue and Rabin (1999).

67 Bernheim and Rangel (2012).

68 Bernheim and Rangel $(2005,5)$.
} 
The literature on this topic is still in its infancy, and a consensus has not yet been reached among scholars. Broadly speaking, engaging in behavioral policy-making requires dealing with two unsolved issues. A first major challenge consists in the identification of preferences once the revealed preference approach is abandoned. A second issue concerns setting precise criteria and standards for abandoning the revealed preference approach.

\subsubsection{Issue 1: Identification of preferences}

Two basic approaches have been advanced for the identification of preferences. First, some scholars propose to identify preferences using choice data through an estimation of structural models that incorporate behavioral assumptions about the decision-making processes. ${ }^{69}$ This process might sound odd at first glance: How is it possible to falsify the revealed preferences principle using choice data only? Indeed, the limitation of these models is that they test the hypothesis of no mistakes jointly with the hypothesis regarding the structure of the decision-making processes that are implicit in the model. Therefore, any evidence of discrepancy between preferences and choices holds as long as the specific non-choice evidence used to motivate the behavioral assumptions of the model holds.

Second, an alternative approach for the identification of preferences consists in combining choice and non-choice data. One possibility advanced first by Kahneman et al. ${ }^{70}$ is to measure individual well-being on the basis of self-reported evaluations of happiness. Kahneman names this approach "experience utility" as opposed to the "decision utility" based on revealed preferences that is usually embraced in economics. Experience utility has received significant attention by economists, and in recent years there have been important methodological advances regarding the possibility of implementing this measure for welfare evaluations. ${ }^{71}$ In particular, some scholars propose to use this measure of utility in the context of policy evaluations and for identifying appropriate societal trade-off. ${ }^{72}$ Moreover, some scholars even argue that happiness should constitute the main goal of policy. ${ }^{73}$ From the perspective of behavioral policy-making, happiness measures of welfare have the advantage of being independent from individual choices. Therefore, people's self-reported happiness, as a consequence of the different choices made, could be employed as a criterion for steering behaviors toward the happiness-maximizing alternative.

However, happiness as a welfare criterion presents several problems. ${ }^{74}$ First, people seem to adapt relatively quickly to circumstances and set the reference point for happiness evaluation accordingly. For instance, empirical evidence shows that

\footnotetext{
69 See, for example, Benkert and Netzer (2015), Goldin (2015), Goldin and Reck (2015) and Laibson et al. (2007).

${ }^{70}$ Kahneman et al. (1997).

71 See, for example, Kahneman et al. (2004) and Frey and Stutzer (2010).

72 Layard and Layard (2011) and Bruni (2007).

73 Duncan (2013).

74 See Loewenstein and Ubel (2008) for a detailed discussion of each of the following points.
} 
people suffering from permanent disabilities place a high value on their health but do not show significant differences in the happiness level if compared with a control sample of non-disabled people. ${ }^{75}$ Hence, measures of welfare grounded on experience utility would suggest policies that fail to capture people's preferences. Moreover, happiness measures are extremely sensible to a wide range of non-normative and volatile factors, such as the happiness of surrounding people, states of mind, emotions, or weather conditions. ${ }^{76}$ These problems question the possibility of using happiness as the welfare criterion for policy analysis.

\subsubsection{Issue 2: Setting precise criteria and standards for abandoning the revealed preference approach}

First, a welfare criterion that does not truly depart from the basic assumption of the preference-based approach is known as "Informed Decision Utility." This criterion requires policy-makers to ensure that agents are truly informed when they are making their choices. Hence, it suggests the provision of warnings against possible decision biases and facilitating agents' gathering of information about the object of choice. Furthermore, in situations where agents tend to underappreciate the risks or the long-term consequences of certain actions, informed decision utility policies expose and make these consequences salient to agents.

One problem with this approach is that policy-makers have to engage in value judgments, deciding which ones require policy interventions among the infinite range of situations where information could be improved. Similarly, information is unlikely to be "neutral": the choice involved might be affected in opposite ways according to the framing of the information provided. Therefore, deciding how to convey the information involves adopting some form of welfare criterion that is not specified. A further limitation of this approach is that it addresses only problems of sub-optimal decisions deriving from a lack of attention or information, but does not offer solutions for mistakes deriving from self-control problems. Either naïve agents unaware of the behavioral biases leading them to poor decisions, or sophisticated individuals that are seeking solutions for their self-control problems would actually derive little benefit from just being told about the problem without being offered a solution.

Second, an interesting proposal is advanced by Bernheim and Rangel. ${ }^{77}$ The authors suggest using findings and advances in applied psychology and neurosciences in order to establish evidence of errors in the brain process mechanisms. While the proposal is intriguing and promising for future applications, unfortunately we are still far from having a knowledge of neuroscience that is sufficiently solid to constitute the pillar of policy analysis.

Therefore, in recent studies Goldin (2015) and Goldin and Reck (2015) propose two approaches to overcome the problem of identifying behavioral preferences that

\footnotetext{
75 Ubel et al. (2005).

76 Kahneman and Krueger (2006).

77 Bernheim and Rangel (2004).
} 
do not abandon the revealed preferences framework. The two approaches, labeled by the authors "Augmented Revelatory Frame Approach" and "Demographic Extrapolation Approach," suggest a way to identify behavioral preferences, respectively, in settings where agents' choices could be observed and in settings where revelatory frames are unavailable. The basic idea underlying the two approaches is that the preferences of the "consistent" or rational agent could be identified and used as a benchmark in order to estimate the deviation of the inconsistent agent. While these approaches represent certainly a step ahead in the identification of a suitable welfare criterion for behavioral policy-making, at the same time they raise critiques and concerns regarding the philosophical underpinning of the conceptual construction. For instance, Infante et al. (2016) argue that the process of "purification" of preferences from behavioral biases presupposes the existence of a dualistic model of human being - an inner rational agent trapped in a psychological shell-that is problematic from a psychological and philosophical perspective. Even more fundamentally, Isoni et al. (2016) question whether observed choices can reveal underlying individual preferences without at the same time shaping them, therefore questioning the possibility of basing the welfare criterion on observed choices.

Fourth, Camerer et al. ${ }^{78}$ have proposed another criterion for abandoning the adoption of behavioral policies. The authors claim that in "ideal" conditions the policy would help people who behave in a sub-optimal manner, but would have no impact on the behavior of the people who already make optimal choices. Hence, default rules or framing alternatives seem to satisfy this criterion, since they may steer inattentive people toward advantageous alternatives without imposing any mandate on others. On the other hand, the authors recognize that many policies, while beneficial for biased agents, would impose costs on those who are rationally choosing the optimal outcome. Hence, they propose a "looser but pragmatic" criterion based on cost-benefit analysis: to implement a policy whenever its aggregate benefits for behaviorally biased individuals exceed the costs imposed on unbiased agents. While this criterion is useful in shifting the discussion from the abstract concepts of autonomy and freedom to the more concrete measures of benefits and costs (where losses of freedom and autonomy are treated as a cost), nonetheless it does not address the main point of finding a welfare measure that is not preference-based.

Finally, a more comprehensive proposal has been advanced by Loewenstein and Haisley. ${ }^{79}$ The authors argue that behavioral policies should be safely implemented when "welfare judgment tends to be relatively straightforward." In order to identify these situations, they propose a set of suitable conditions:

- Dominance: there are frequent situations in which people simply "leave money on the table," as in the case of an employee who could contribute to her savings account, benefitting from the employer's matching contribution and withdraw the full deposit the same day without penalty. ${ }^{80}$ Unless we rely on the unrealis-

\footnotetext{
78 Camerer et al. (2003).

79 Loewenstein and Haisley $(2008,221)$.

80 Choi et al. (2011).
} 
tic assumption that people show non-monotonic preferences for money, in these situations it is clear that some behavioral bias is the cause of sub-optimal decision outcomes. This criterion could also be extended to stochastic dominance. According to stochastic dominance, policy interventions are justified if, in a situation involving an agent's choice with risks, the returns are maximized at any possible level of risk. For example, people including their own stock in their retirement portfolio show a behavior that violates stochastic dominance.

- Clearly Negative Outcomes: sometimes people's decisions generate outcomes that are detrimental from any perspective. For example, many householders in the USA borrow from credit cards at a rate of approximately $18 \%$ and at the same time lend money getting a fixed return of $6 \% .^{81}$ In a situation like this, people simply fail to take advantage of an arbitrage opportunity, leaving therefore money on the table. Behavioral policy interventions seem not to require further justification in similar situations.

- Self-officiating: Obese people, gamblers, or drug addicts constantly report that they would be better off were they able to modify their behavior regarding food, gambling, or drug consumption. In these situations, it seems reasonable to implement libertarian paternalistic policies to help them to achieve the desired goals. Loewenstein and Haisley ${ }^{82}$ state this condition specifying that they embrace a concept of welfare based on preferences rather than choices. In fact, the authors recognize that in certain situations behavioral biases might drive individual choices in directions not reflecting inherent preferences.

\subsection{The impasse of behavioral policy-making}

As this section so far has been made clear, the legal scholars pointing at potential limits and issues of behavioral policy-making ${ }^{83}$ can be supported from a law and economics approach as well. Behavioral policy-making violates the four core assumptions on which policy-making on the basis of welfare economic analysis was grounded. The problem is that we equally noted that an alternative for the revealed preference approach has not yet been developed in the literature in a satisfactory manner. The alternatives of deducting preferences from other approaches than the revealed preferences have their own limitations. It seems, for example, unsatisfactory to base policy-making on the criterion of happiness. The second problem we identified is that a clear alternative with specific benchmarks for abandoning the revealed preference approach is also missing. Only the study by Loewenstein and Haisley mentioned above suggests a few basic conditions for when behavioral policy-making could be assumed to make individuals better off. Considering the current lack of an alternative comprehensive theory which could replace the revealed preference approach, we propose to use a procedural solution which would limit the possibility for the government to engage in behavioral interventions to those situations

\footnotetext{
81 Sunstein and Thaler (2003).

82 Loewenstein and Haisley (2008).

83 McCrudden and King (2015), Alemanno and Spina (2014), Van Aaken (2015a) and Young (2012).
} 
where it is most likely that the policy would indeed make individuals better off without the government abusing its powers.

\section{The way out: establishing the rules of the game for behavioral policy-making through "constitutional-type" guiding principles}

We have indicated that, both from a legal and from a law and economics perspective, issues arise as far as the unrestricted use of behavioral policy-making is concerned. The problem from a law and economics perspective is that, if policy-making is no longer based on the normative welfare criterion of revealed preferences, it is not clear on which criterion the policy-maker will base interventions. This always entails the risk that the policy-maker will paternalistically decide what is "best" for individuals, whereas it is not always clear that the intervention will indeed satisfy their preferences. The problems identified from a legal perspective relate, inter alia, to the undemocratic nature of nudging, the lack of possibilities of legal review (which are instead possible in the case of formal regulation), the fact that behavioral interventions may violate autonomy and liberty of individuals and especially that it is not the democratically elected legislator, but rather the executive, who would be the "choice architect" and hence decide how to "nudge." 84

In order to limit these dangers, we propose that behavioral policy-making must adhere to "constitutional-type" guiding principles, where the conditions, under which behavioral policy-making would be possible, are clearly stipulated. ${ }^{85}$ Formulating a constitution as a device whereby citizens collectively agree on the conditions under which certain measures can be taken has been often proposed in legal and law and economics scholarship. For instance, in light of terrorism a state of emergency is declared, which would justify taking exceptional measures. It is precisely for that reason that Bruce Ackerman held that "before the next attack" the conditions under which civil liberties can be limited or restricted should be carefully defined. ${ }^{86}$ The author works out a detailed system in which, depending upon the nature of the threat or danger, specific exceptions to civil liberties are possible, but where each time a board will also have to verify whether the specific conditions to justify the restrictions on civil liberties are still present. As Ackerman stresses, there are many advantages in specifying those conditions in a correct procedure ex ante, precisely in order to prevent civil liberties from being jeopardized in a disproportionate manner.

From an economic perspective, the advantage of such constitutional-type rules is that they (1) require a super majority to change and (2) set forth the fundamental powers, duties, and structure of the government. ${ }^{87}$ These particular features would make constitutional-type rules attractive for behavioral policy-making. The

\footnotetext{
84 See, inter alia, Van Aaken (2015a).

85 The proposal for a "constitution" for behavioral policy-making has been advanced in the literature also by Frey and Gallus (2016). However, the authors do not develop the idea further in the article.

86 Ackerman (2006, 77-100).

87 Posner (2011, 867) and Posner (1987).
} 
advantage would be that these rules would make it clear in which conditions the government could make use of behavioral policies and, perhaps more importantly, when it could not do so. Hence, constitutional-type guiding principles would set out what the rules of the game are and provide a unifying framework for behavioral policy-making, an aspect which is currently lacking. This set of rules would indicate when behavioral policies could be used, hence avoiding the criticism that it is the executive alone that, in a paternalistic manner, exploits behavioral interventions to impose its own choices.

In this sense, our proposal has some points in common with the argument developed by Buchanan and Tullock in the book "The Calculus of Consent: Logical Foundations of Constitutional Democracy." 88 The authors argue that the normal dialectic of majoritarian democracies implies that, when voting on specific decisions, the majority imposes its view and tramps minorities' interests. In this sense, the democratic process is authoritarian when deciding about specific policies. However, according to Buchanan and Tullock, the fundamental aspect of the democratic process is that the majority and the minority agree ex ante on a set of constitutional rules concerning how decisions are made. Therefore, some rule for unanimity or full consent at the constitutional level of decision making is the necessary ingredient for democracies to work, while an agreement on specific policy issues between agents or coalitions involved in the political process is not a necessary condition. As it is the case for the constitutional rules prescribed by Buchanan and Tullock, also our proposal for constitutional-type guidelines for behavioral policy-making concerns the need for policy-makers and political parties to agree ex ante on a set of rules that specify the conditions necessary for the implementation of behavioral public policies and for the procedures to follow thereafter. Given this general framework, the implementation of specific behavioral policies by the executive would be constrained by the limits that actors have explicitly agreed upon, thus reducing concerns for potential misuses of this policy tool.

In the remainder of this section, we suggest four key components that should characterize constitutional-type guiding principles for behavioral policy-making.

\subsection{Independent decision making}

One important aspect of the constitutional-type rules is that they should make clear what the specific procedure is with which the government could engage in behavioral policy-making. When particular criteria for allowing behavioral interventions have been determined, their decision making could be entrusted to an independent agency, consisting of experts, in psychology, economics, philosophy and law, who would examine whether in the particular case the conditions specified have been fulfilled. Entrusting the decision making to an independent agency that stands at some distance of the government would avoid some of the current political economy

88 Buchanan and Tullock (1962). 
issues of behavioral policy-making. ${ }^{89}$ The role of the agency could be comparable to those used, for example, in risk regulation (or food safety), where a risk assessment is equally undertaken by a committee of independent experts. ${ }^{90}$

Moreover, in risk regulation it has often been stressed that a distinction should be made between risk assessment, which involves expert knowledge, and a broader assessment stage. In this second stage, the agency should also seek non-experts opinions, including minority views, to get a good grasp of, for example, the risks involved with introducing new technologies. ${ }^{91}$ Indeed, the scope of this second assessment is much broader and should include noneconomic considerations, such as the efficacy of possible options and their acceptability to the public. That is because the decision concerning, for instance, admitting a risky drug of which neither the benefits nor the costs are fully known, is not considered simply a technical decision. Hence, after the (technical) risk assessment in the risk management phase, other types of interests and observations should also be included before coming to a final decision. This multi-level procedure is reflected in the 2000 Communication on the Precautionary Principle of the European Commission. ${ }^{92}$ The Communication provides thus an important precedent for how an independent agency could take measures based on behavioral insights. Experts, for instance in cognitive psychology and behavioral economics, could in a first phase enlighten the policy-maker of the likely effect of particular measures for the majority of the population. However, in a second phase a broader debate could take place, including also the question whether the policy instruments, which would be based on behavioral insights and certain policies making use of behavioral interventions, would be considered as acceptable, in light of the potential of violating individual autonomy and liberty. The advantages that in the design of such a committee the policy-maker can rely on the experience in the field of risk regulation where it has, inter alia, been clarified how independent agencies can be structured in such a way that they work in the public interest. ${ }^{93}$

Interestingly, the EU communication equally held that measures taken on the basis of the precautionary principle ${ }^{94}$ should also be periodically reviewed in light of scientific progress and amended as necessary. We will come back to this point in subsection 4.4 .

\footnotetext{
${ }^{89}$ McCrudden and King criticize nudging for strongly fulfilling the agenda of a conservative-led government in the UK (McCrudden and King 2015, 117-121).

${ }^{90}$ See Vos (2013) and Vos and Wendler (2006).

${ }^{91}$ See, inter alia, Bouder and Lofstedt (2013) and Alemanno (2014).

${ }^{92}$ EU Commission, Communication on the Precautionary Principle, COM(2000), 1. See on this difference between risk assessment and risk management also Christoforou (2004) and Wiener (2004). The Communication holds that evaluating whether a particular (new) technology should be allowed in the face of uncertainty should start with a scientific evaluation identifying the degree of scientific uncertainty. This is referred to as risk assessment. However, in a second phase, referred to as risk management, decision makers have to take the political responsibility to determine the "acceptable" level of risk for society.

93 An important element in this respect is the accountability of agency decisions (see Bovens 2007), but equally the possibility of public participation.

94 This principle broadly holds that scientific uncertainty in itself may not be a reason for a lack of action. For details, see Faure and Skogh (2003, 21-26).
} 


\subsection{Meaningful public participation}

Just as in the debate with respect to risk regulation, one could equally envisage that the decision concerning behavioral policy-making would also involve public participation. ${ }^{95}$ Again, this relies on a parallel with risk regulation where, at the stage of risk management, public participation may be involved. Obviously, this process has to be carefully organized. ${ }^{96}$

The advantage is that with this procedure some of the problems that lawyers have with behavioral policy-making as being undemocratic and showing insufficient respect for individual autonomy, liberty, or dignity could partially be tackled. ${ }^{97}$ Indeed, the decision to use behavioral interventions in a specific domain would not rely solely on the expert opinion (on the usefulness and relative efficiency of the policy) but also on opinions of the public (on whether the particular nudge would be desirable and would not constitute a disproportional infringement on autonomy and individual liberty).

One issue is, however, that the literature indicating criteria for increasing the quality of agency decisions not only points to the importance of public participation in order to achieve democratic goals, but also points to transparency. ${ }^{98}$ But a problem with nudging is that it "works best in the dark," the nudge may reduce its effectiveness. Hansen and Jespersen have, however, indicated that it is possible to have some degree of transparency without necessarily reducing the effectiveness of nudging. ${ }^{100}$

\subsection{Defining intervention domains}

That brings us then to the contents of the test: constitutional-type guiding principles should indicate guidelines stating when behavioral policy interventions are allowed (and when not). ${ }^{101}$ One such guideline could be the principle of evidence mentioned above $^{102}$ : People have to leave money on the table, in which case the advantages of the nudge for any group are undisputed. Another guideline is the principle of stochastic dominance, which state that an individual decision can only be overturned, providing that this decision results stochastically dominated for any possible

\footnotetext{
95 Again there is a parallel with risk regulation. After the BSE crisis, the importance of transparency and public participation in the decision making concerning food safety has equally been stressed in the literature and been incorporated at the policy level. See in that respect, inter alia, Vos (2013, 43-46); and see the contributions in Vos and Wendler (2006).

96 And to guarantee that such public participation takes place in an informed manner. See in that respect inter alia Lofstedt et al. (2011) and Lofstedt (2014).

97 For an example of legal problems that nudges could potentially face, see Van Aaken (2015b) who proposes a thorough analysis of the constitutional limits of nudging in the context of German law.

98 See inter alia Coglianese et al. (2008).

99 Bovens $(2008,4)$ and Hansen and Jespersen $(2013,9)$.

100 Hansen and Jespersen (2013, 15-23).

101 For an alternative framework for a "responsible use of the nudge approach to behavior change" see the typology developed by Hansen and Jespersen (2013, 23-27).

102 See 3.2.2 in fine.
} 
outcome. For instance, an individual investing all his savings in stocks of the companies where he is currently employed shows a lack of understanding of the risks connected with his decision. Also, the principle of clearly negative outcomes (when it is clear that people's decisions generate outcomes that are detrimental in any perspective) and the principle of self-officiating (where individuals explicitly recognize that in particular situations behavioral biases drive their choices in directions not reflecting their preferences, like with gambling or drug consumption) could drive behavioral policy-making.

A further differentiation which can be reflected in the "constitution" is that the desirability of behavioral interventions may differ according to the various fields of the law. A distinction could be made in that respect between domains of the law where the explanatory power of the behavioral approach (as well as the policy recommendations) is relatively strong on the one hand and domains where that explanatory power is substantially weaker. For example, the case for behavioral interventions is usually better accepted in the case of consumer law, for example when informational remedies are suggested ${ }^{103}$ or in the case of standard form contracts. ${ }^{104}$ It is, on the contrary, much more debated in the area of competition law where one author qualified behavioral antitrust as "not ready for the main stage." 105 It should be recalled that the criticism we formulated concerning the lack of an alternative paradigm for the revealed preferences approach is a general one and therefore applies to any field of law. However, some interventions, suggested by the behavioral approach, may in particular domains of law be more in line with the traditional criteria of welfare maximization than others and could therefore better fit in behavioral policy-making. A further differentiation of different fields of law and different types of legal rules in the "constitution" may therefore better define the boundaries of the use of behavioral insights. A logical consequence would be to limit interventions to legal domains and policy interventions where the literature considers the tension with the goal of welfare maximization. Finally, different types of behavioral interventions should be treated differently, according to the degree of violation of individual autonomy. For instance, rules for simplifying information can be less stringent than for nudges exploiting behavioral regularities to redirect behavior. Indeed, evidence shows that people have heterogeneous levels of appreciation for different types of nudges (Sunstein forthcoming).

To summarize the basic idea behind constitutional-type guidelines for defining intervention domains, we quote a passage from Ogus, where the author formulates some general criteria to evaluate paternalistic regulation that could equally apply to behavioral policy-making ${ }^{106}$ :

\footnotetext{
103 See general Bar-Gill (2012) and Sibony (2014).

104 Faure and Luth (2011).

105 Van den Begh (2013).

106 Ogus $(2006,312)$.
} 
- are there plausible traditional justifications (externalities, information failure, inadequate competition) for the measure, operating independently of paternalism?

- if not, and taking account of the insights of social psychology, is the regulated activity one with regard to which a significant proportion of the agents make decisions that are unlikely to reflect their real preferences?

- if so, are the likely costs of the regulatory measure proportionate to the likely benefits and/or could the same be reached at lower cost by an alternative instrument?.

\subsection{Sunset clauses}

Another procedural aspect that could be included is that behavioral policies could be implemented as so-called sunset laws. ${ }^{107}$ A sunset clause causes a statute to expire on a legally specified date. ${ }^{108}$ Sunset clauses allow the legislator to govern for a specific limited time. Sunset clauses differ from simple ex post evaluations of a policy or legal provision effect because, in order to be renewed, the clause must be explicitly re-discussed and re-approved. Law and economics scholarship has shown that sunset clauses are more particularly introduced in socially normative and often controversial legislation such as, for example, legislation regulating gun control in the US or domestic surveillance. ${ }^{109}$ Temporary legislation (including a sunset clause) may be easier to enact also in controversial policy domains because it governs for a shorter period of time. ${ }^{110}$ The major advantage is that it is generally held that this type of legislation allows for an ex post evaluation and learning mechanism. ${ }^{11}$ If this evaluation shows that the rules were effective, then they can be adapted and converted into permanent laws. ${ }^{112}$

Those arguments may equally apply to the case of behavioral policy-making which is, as one can see from the criticism in both economic and legal scholarship, of a controversial nature. Moreover, scholars encourage the implementation of behavioral policies following experimental procedures in order to facilitate their impact evaluation. ${ }^{113}$ The advantage of introducing behavioral policies with a sunset clause is that it facilitates the experiment, while at the same time limiting its duration. An experimental implementation coupled with a sunset clause has, on the one hand, the advantage that the impact of the behavioral policy on the outcome of interest can be estimated. On the other hand, this procedure forces the regulator to base

\footnotetext{
107 Within the scope of this article, we discuss this suggestion separately, but obviously this could be included in the "constitution" as well.

108 Fagan (2011, 11), Van Gestel and Van Dijck (2011) and Bar-Siman-Tov (2015).

109 Fagan $(2011,12)$.

110 Fagan $(2011,14)$.

111 Bar-Siman-Tov $(2015,5)$.

112 Van Gestel and Van Dijck (2011).

113 McCrudden and King $(2015,111)$.
} 
behavioral policy-making (and the eventual extension of sunset clauses) on available evidence. Furthermore, to the extent that behavioral policy-making would have negative or unpredicted consequences (as held by McCrudden and King, ${ }^{114}$ who referred to "the dark side of nudging"), the advantage of a sunset clause is that these effects would be limited in time.

\section{Concluding remarks}

As of today, behavioral policy-making had been criticized from various perspectives both in legal and in economic scholarship. Apparently, this criticism has so far not been impressed policy-makers, with whom behavioral policy-making remains increasingly popular. One reason for the lack of influence of the criticisms advanced is possibly that many overlook the issues and possible consequences of the problematic theoretical foundations that characterize behavioral policy-making. This is worrying to the extent that, while "traditional" policy-making might be imperfect, it is at least based on a theory (of revealed preferences) that is freedom preserving. Indeed, according to the theory of revealed preferences, policy-makers in designing interventions are bound to respect what individuals choose. Conversely, behavioral policy-making states that observed individuals choices can be the product of biases and mistakes. This entitles governments and policy-makers to decide upon the relevant welfare criterion for policy-making, opening up the possibility of engaging in freedom-reducing activities under the justification that those activities are "detrimental to social welfare." Policy-makers seem to underestimate the potential problems arising from the theoretical issues characterizing behavioral policy-making to the same extent that brokers using complex financial instruments a few years ago equally overlooked the actual degree of risk of these products, a fact that contributed to the financial crisis. ${ }^{115}$ Unfortunately, a theoretic alternative to the revealed preferences approach that would provide a foundation for behavioral policy-making has not yet been advanced. Therefore, in the absence of a well-defined theoretical framework to establish a suitable welfare criterion, we suggest a pragmatic solution based on a definition of boundaries and clear procedures to deal with behavioral policymaking. ${ }^{116}$ We propose the establishment of general rules constraining the powers of the behavioral policy-maker through "constitutional-type" guidelines for behavioral policy interventions.

This constitution will on the one hand provide clear criteria for situations where behavioral policy interventions could be warranted and where traditional interventions are more proper. On the other hand, it would specify a procedure, preferably

\footnotetext{
114 McCrudden and King (2015, 83-84).

115 Stiglitz (2011). Similarly, Nicole El Karoui, the famous French scholar from the University of Paris VI who elaborated the mathematical foundations on which the flawed derivative models that generated the 2008 financial crisis were constructed, states: "At times [mathematicians] have behaved like engineers who design cars that are too fast...Perhaps the mathematicians have not explained well the risks of these products." Il Sole 24 Ore, 26 ottobre 2008.

116 For example by Loewenstein and Haisley $(2008,221)$.
} 
allocating power to an independent neutral agency that verifies whether sufficient conditions for behavioral intervention are fulfilled. A related procedural requirement would be that stakeholders are involved in the decision-making process. Finally, behavioral policies should be accompanied with a sunset clause allowing for experimentation but at the same time limiting the potentially negative consequences of a behavioral intervention. While awaiting solid economic theories that will form the basis of enlightened behavioral policy-making, we encourage to set out clear procedures and safety boundaries regulating the use of this policy tool.

Acknowledgements We are grateful to Wenqing Liao and Mengxing Lu (Maastricht) for useful research assistance, to Elena Kantorowicz-Reznichenko (Rotterdam Institute of Law and Economics), Roger Van den Bergh (Rotterdam Institute of Law and Economics), Massimiliano Vatiero (USI, Lugano), and to the participants in a BACT lunch seminar (Rotterdam, June 2016) and in the Annual Conference of the European Association for Law and Economics (London, September 2017) for useful comments on an earlier version of this paper. The usual disclaimer applies.

\section{Compliance with ethical standards}

Conflict of interest The authors declare that they have no conflict of interest.

Open Access This article is distributed under the terms of the Creative Commons Attribution 4.0 International License (http://creativecommons.org/licenses/by/4.0/), which permits unrestricted use, distribution, and reproduction in any medium, provided you give appropriate credit to the original author(s) and the source, provide a link to the Creative Commons license, and indicate if changes were made.

\section{References}

Ackerman B (2006) Before the next attack: preserving civil liberties in an age of terrorism. Yale University Press, New Haven

Adler M (2012) Well-being and fair distribution: beyond cost-benefit analysis. Oxford University Press, Oxford

Akerlof GA, Shiller RJ (2010) Animal spirits: how human psychology drives the economy, and why it matters for global capitalism. Princeton University Press, Princeton

Alemanno A (2014) What role for a chief scientist in the European Union System of scientific advisor? Eur J Risk Regul 5:236-292

Alemanno A, Spina A (2014) Nudging legally: on the checks and balances of behavioral regulation. Int J Const Law 12:429-456

Ameriks J, Caplin A, Leahy J, Tyler T (2007) Measuring self-control problems. Am Econ Rev 97:966-972

Ariely D, Jones S (2008) Predictably irrational. HarperCollins, New York

Ayres I (2010) Carrots and sticks: unlock the power of incentives to get things done. Bantam, New York

Bar-Gill O (2012) Seduction by contract law: law, economics and psychology in consumer markets. Oxford University Press, Oxford

Bar-Siman-Tov I (2015) Temporary legislation, better regulation and experimentalist governance: an empirical study. http://papers.ssrn.com/sol3/papers.cfm?abstract_id=2807564. Accessed 10 Mar 2017

Benkert J-M, Netzer N (2015) Informational requirements of nudging. CESifo working paper, No. 5327, Group Munich

Bernheim BD, Rangel A (2004) Addiction and cue-triggered decision processes. Am Econ Rev 94:1558-1590

Bernheim BD, Rangel A (2005) Behavioral public economics: welfare and policy analysis with nonstandard decision-makers. Tech. rep., National Bureau of Economic Research 
Bernheim BD, Rangel A (2012) Behavioral public economics: welfare and policy analysis with nonstandard decision-makers. Princeton University Press, Princeton

Beshears J, Choi JJ, Laibson D, Madrian BC (2008) How are preferences revealed? J Public Econ 92(8-9):1787-1794

Beshears J, Choi J, Laibson D, Madrian BC, Weller B (2010) Public policy and saving for retirement: the autosave features of the pension protection act of 2006. In: Siegfied JJ (ed) Better living through economics. Harvard University Press, Cambridge, pp 274-290

Bouder F, Lofstedt RE (2013) Risk. Routledge, Oxon

Bovens M (2007) Analysing and assessing accountability: a conceptual framework. Eur Law J 13(a):447-468

Bovens L (2008) The Ethics of Nudge. In: Grüne-Yanoff T, Hansson SO (eds) Preference change: approaches from philosophy, economics and psychology. Springer, Berlin, pp 207-219

Bruni L (2007) Handbook on the economics of happiness. Edward Elgar Publishing, Cheltenham

Buchanan J-M, Tullock G (1962) The calculus of consent, vol 3. University of Michigan Press, Ann Arbor

Camerer C, Loewenstein G (2004) Behavioral economics: past, present, future. Princeton University Press, Princeton

Camerer C, Issacharoff S, Loewenstein G, O’Donoghue T, Rabin M (2003) Regulation for conservatives: behavioral economics and the case for 'asymmetric paternalism'. University of Pennsylvania Law Review 151(3):1211-1254

Camerer CF, Loewenstein G, Rabin M (2004) Advances in behavioral economics. Princeton University Press, Princeton

Carroll GD, Choi JJ, Laibson D, Madrian BC, Metrick A (2009) Optimal defaults and active decisions. Q J Econ 124(4):1639-1674

Choi JJ, Laibson D, Madrian BC, Metrick A (2003) Optimal defaults. Am Econ Rev 93:180-185

Choi JJ, Laibson D, Madrian BC (2011) \$100 bills on the sidewalk: suboptimal investment in $401(\mathrm{k})$ plans. Rev Econ Stat 93(3):748-763

Christoforou Th (2004) The precautionary principle, risk assessment, and the comparative role of science in the European Community and the US Legal Systems. In: Vig NJ, Faure MG (eds) Green giants? Environmental policies of the United States and the European Union. MIT Press, Cambridge, pp 17-52

Cialdini RB, Trost MR (1998) Social influence: social norms, conformity and compliance. McGraw-Hill, New York

Coglianese C, Kilmartin H, Mendelson E (2008) Transparency and public participation in the federal rulemaking process: recommendations for the new administration. George Wash Law Rev 77:924-972

Congdon WJ, Kling JR, Mullainathan S (2011) Policy and choice: public finance through the lens of behavioral economics. Brookings Institution Press, Washington

Della Vigna S (2009) Psychology and economics: evidence from the field. J Econ Lit 47:315-372

Duncan G (2013) Should happiness-maximization be the goal of government? In: Delle Fave A (ed) The exploration of happiness. Springer, Vienna, pp 303-320

Engel C (2011) Dictator games: a meta study. Exp Econ 14(4):583-610

Epstein RA (2006) Behavioral economics: human errors and market corrections. Univ Chic Law Rev 73(1):111-132

Epstein RA (2008) The neo-classical economics of consumer contracts. Minn Law Rev 92(3):803-835

Fabbri M, Carbonara E (2017) Social influence on third-party punishment: an experiment. J Econ Psychol 62:204-230

Fagan FJ (2011) Temporary versus permanent legislation. Diss. Erasmus School of Law

Faure MG, Luth HA (2011) Behavioural economics in unfair contract terms. Cautions and considerations. J Consum Policy 34:337-358

Faure M, Skogh G (2003) The economic analysis of environmental policy and law: an introduction. Edward Elgar, Cheltenham

Fehr E, Schmidt KM (1999) A theory of fairness, competition, and cooperation. Q J Econ 114:817-868

Frey BS, Gallus J (2016) Beneficial and exploitative nudges. In: Mathis K, Thor A (eds) Nudging-possibilities, limitations and applications in European law and economics. Springer, Cham, pp 11-20

Frey BS, Stutzer A (2010) Happiness and economics: how the economy and institutions affect human well-being. Princeton University Press, Princeton 
Gigerenzer G (2005) Is the mind irrational or ecologically rational? In: Parisi F, Smith VL (eds) The law and economics of irrational behavior. Stanford University Press, Stanford, pp 37-67

Glaser EL (2006) Paternalism and psychology. Univ Chic Law Rev 73:133-156

Goldin J (2015) Which way to nudge? Uncovering preferences in the behavioral age. Yale Law J 125(1):226-270

Goldin J, Reck DH (2015) Preference identification under inconsistent choice. Available at SSRN 2417709

Gul F, Pesendorfer W (2001) Temptation and self-control. Econometrica 69(6):1403-1435

Gul F, Pesendorfer W (2004) Self-control and the theory of consumption. Econometrica 72(1):119-158

Gul F, Pesendorfer W (2005) The case for mindless economics. Princeton University

Hansen PG (2016) The definition of nudge and libertarian paternalism: does the hand fit the glove? Eur J Risk Regul 1:1-20

Hansen PG, Jespersen AM (2013) Nudge and the manipulation of choice. A framework for the responsible use of the nudge approach to behavioral change in public policy. Eur J Risk Regul 1:3-28

Hsu M, Bhatt M, Adolphs R, Tranel D, Camerer CF (2005) Neural systems responding to degrees of uncertainty in human decision-making. Science 310(5754):1680-1683

Infante G, Lecouteux G, Sugden R (2016) Preference purification and the inner rational agent: a critique of the conventional wisdom of behavioural welfare economics. J Econ Methodol 23:1-25

Isoni A, Brooks P, Loomes G, Sugden R (2016) Do markets reveal preferences or shape them? J Econ Behav Organ 122:1-16

Jolls Chr (1998) Behavioral economic analysis of redistributive legal rules. Vanderbilt Law Rev 51:1653-1677

Jolls Chr, Sunstein CR, Thaler R (1998) A behavioral approach to law and economics. Stanf Law Rev 50:1471-1550

Kahneman D (2003) Maps of bounded rationality: psychology for behavioral economics. Am Econ Rev 93:1449-1475

Kahneman D (2011) Thinking, fast and slow. Macmillan, New York

Kahneman D, Krueger AB (2006) Developments in the measurement of subjective well-being. J Econ Perspect 20(1):3-24

Kahneman D, Slovic P, Tversky A (eds) (1982) Judgment under uncertainty: heuristics and biases. Cambridge University Press, Cambridge

Kahneman D, Wakker PP, Sarin R (1997) Back to Bentham? Explorations of experienced utility. Q J Econ 112:375-405

Kahneman D, Krueger AB, Schkade DA, Schwarz N, Stone AA (2004) A survey method for characterizing daily life experience: the day reconstruction method. Science 306(5702):1776-1780

Korobkin RB, Ulen TS (2000) Law and behavioral science: removing the rationality assumption from law and economics. Calif Law Rev 88:1055-1144

Laibson D (1997) Golden eggs and hyperbolic discounting. Q J Econ 112(2):443-478

Laibson D, Repetto A, Tobacman J (2007) Estimating discount functions with consumption choices over the lifecycle. Tech. rep., National Bureau of Economic Research

Layard PRG, Layard R (2011) Happiness: lessons from a new science. Penguin Books, London

List JA (2003) Does market experience eliminate market anomalies. Q J Econ 118(1):41-71

List JA (2006) The behaviorist meets the market: measuring social preferences and reputation effects in actual transactions. J Polit Econ 114:1-37

Loewenstein G (1996) Out of control: visceral influences on behavior. Organ Behav Hum Decis Process 65(3):272-292

Loewenstein G, Haisley E (2008) The economist as therapist: methodological ramifications of 'light' paternalism. In: Caplin ASA, Schotter A (eds) The foundations of positive and normative economics: a handbook of economic methodologies. Oxford University Press, Oxford, pp 210-245

Loewenstein G, O’Donoghue T (2004) Animal spirits: affective and deliberative processes in economic behavior. Available at SSRN 539843

Loewenstein G, Ubel PA (2008) Hedonic adaptation and the role of decision and experience utility in public policy. Journal of Public Economics 92(8):1795-1810

Lofstedt R (2014) A possible way forward for evidence-based and risk-informed policy-making in Europe: a personal view. J Risk Res 17:1089-1108

Lofstedt R, Bouder F, Wardman J, Chakraborty S (2011) The changing nature of communication and regulation of risk in Europe. J Risk Res 14:409-429 
Lourenço JS, Ciriolo E, Almeida SR, Troussard X (2016) Behavioural insights applied to policy, European Report 2016. EUR 27726 EN. https://doi.org/10.2760/903938

Lunn P (2014) Regulatory policy and behavioural economics. OECD Publishing, Paris

McCrudden Chr, King J (2015) The dark side of nudging: the ethics, political economy, and law of libertarian paternalism. Michigan Law, Public Law and Legal Theory Research Paper Series, Paper No. 485, November 2015. http://ssrn.com/abstract=2685832. Accessed 5 July 2017

Mullane M, Sheffrin S (2012) Regulatory nudges in practice (paper prepared for the Conference on Responsible Regulation), Tulane. http://murphy.tulane.edu/files/events/Regulatory_Nudges_ feb_24.pdf. Accessed 20 Aug 2017

Nussbaum MC (1997) Flawed foundations: the philosophical critique of (a particular type of) economics. Univ Chic Law Rev 64(4):1197-1214

Nussbaum MC (2001) Women and human development: the capabilities approach, vol 3. Cambridge University Press, Cambridge

O’Donoghue T, Rabin M (1999) Doing it now or later. Am Econ Rev 89:103-124

O’Donoghue T, Rabin M (2001) Choice and procrastination. Q J Econ 116(1):121-160

Ogus AI (2006) Costs and cautionary tales, economic insights for the law. Hart Publishing, Oxford

Posner RA (1987) The constitution as an economic document. George Wash Law Rev 56:4-38

Posner RA (1998) Rational choice, behavioral economics, and the law. Stanf Law Rev 50:1551-1575

Posner RA (2011) Economic analysis of law, 8th edn. Aspen Publishers, New York

Rebonato R (2012) Taking liberties: a critical examination of libertarian paternalism. Palgrave Macmillan, London

Samuelson PA (1938) A note on the pure theory of consumer's behaviour. Economica 5(17):61-71

Sen A (1985) Commodities and capabilities. Professor Dr. P. Hennipman lectures in economics: theory, institutions, policy

Sen A (1999) Development as freedom. Oxford University Press, Oxford

Sibony AL (2014) Can EU consumer law benefit from behavioral insights? An analysis of the unfair practices directive. Eur Rev Private Law 6:901-942

Stiglitz JE (2011) Of the $1 \%$, by the $1 \%$, for the $1 \%$. VF News, March 2011. http://www.vanityfair.com/ news/2011/05/top-one-percent-201105. Accessed 5 July 2017

Sugden R (2004) The opportunity criterion: consumer sovereignty without the assumption of coherent preferences. Am Econ Rev 94:1014-1033

Sunstein, Cass R (forthcoming) Do people like nudges? Adm Law Rev. https://ssrn.com/abstract=26040 84 or https://doi.org/10.2139/ssrn.2604084. Accessed 10 Mar 2016

Sunstein CR (1997) Behavioral analysis of law. The University of Chicago Law Review 64:1175-1195

Sunstein CR (1999) Behavioral law and economics: a progress report. Am Law Econ Rev 1(1):115-157

Sunstein CR (ed) (2000) Behavioral law and economics. Cambridge University Press, Cambridge

Sunstein CR, Thaler RH (2003) Libertarian paternalism is not an oxymoron. Univ Chic Law Rev 70:1159-1202

Thaler RH, Benartzi S (2004) Save More Tomorrow ${ }^{\mathrm{TM}}$ : using behavioral economics to increase employee saving. J Polit Econ 112(S1):S164-S187

Thaler RH, Sunstein CR (2003) Libertarian paternalism. Am Econ Rev 93:175-179

Thaler RH, Sunstein CR (2008) Nudge. Improving decisions about health, wealth and happiness. Yale University Press, New Haven

The World Bank (2015) World development report: mind, society, and behavior. The World Bank, Washington

Tor A (2008) The methodology of the behavioral analysis of law. Haifa Law Rev 4(1):237-327

Tversky A, Kahneman D (1974) Judgment under uncertainty: heuristics and biases. Science 185:1124-1131

Tversky A, Kahneman D (1981) The framing of decisions and the psychology of choice. Science 211(4481):453-458

Tversky A, Kahneman D (1986) Rational choice and the framing of decisions. J Bus 59:S251-S278

Ubel PA, Loewenstein G, Schwarz N, Smith D (2005) Mismanaging the unimaginable: the disability paradox and health care decision making. Health Psychol 24(4S):S57-S62

Van Aaken A (2015a) Judge the nudge: in search of legal limits of paternalistic nudging in the EU. In: Alemanno A, Sibony AL (eds) Nudging and the law: what can EU law learn from the behavioral sciences?. Hart Publishing, Oxford, pp 83-112

Van Aaken, A. (2015) Constitutional limits to nudging: a proportionality assessment. University of St. Gallen Law \& Economics Working Paper 3 
Van den Begh RJ (2013) Behavioral antitrust: not ready for the main stage. J Compet Law Econ 9(1):203-229

Van Gestel RAJ, Van Dijck G (2011) Better regulation through experimental legislation. Eur Public Law 17(3):539-553

Vos E (2013) Promoting food safety trough legal measures in developing countries: experiences from EU food safety regulation. In: Faure M, Wibisana A (eds) Regulating disasters, climate change and environmental harm. Lessons from the Indonesian experience. Edward Elgar, Cheltenham, pp 38-55

Vos E, Wendler F (eds) (2006) Food safety regulation in Europe: a comparative institutional analysis. Antwerp, Intersentia

Wiener JB (2004) Convergence, divergence and complexity in US and European risk regulation. In: Vig NJ, Faure MG (eds) Green giants? Environmental policies of the United States and the European Union. MIT Press, Cambridge, pp 73-110

Young K (2012) Nudge as a fudge. Modern Law Review 75:122-137 